Project 1024646

\title{
Reaction-Based Reactive Transport Modeling of Fe(III) and U(V) Reduction
}

\author{
Burgos, William D. \\ Pennsylvania State University \\ Roden, Eric E. \\ University of Alabama \\ Yeh, Gour-Tsyh \\ University of Central Florida
}

RESULTS TO DATE: Our new research project (started Fall 2004) was funded by a grant to The Pennsylvania State University, University of Central Florida, and The University of Alabama in the Integrative Studies Element of the NABIR Program (DE-FG04-ER63914/63915/63196). Our previous NABIR project (DE-FG02-01ER63180/63181/63182, funded within the Biotransformation Element) focused on (1) microbial reduction of $\mathrm{Fe}(\mathrm{III})$ and $\mathrm{U}(\mathrm{VI})$ individually, and concomitantly in natural sediments, (2) Fe(III) oxide surface chemistry, specifically with respect to reactions with Fe(II) and U(VI), (3) the influence of humic substances on $\mathrm{Fe}(\mathrm{III})$ and $\mathrm{U}(\mathrm{VI})$ bioreduction, and on $\mathrm{U}(\mathrm{VI})$ complexation, and (4) the development of reaction-based reactive transport biogeochemical models to numerically simulate our experimental results. The new project focuses on the development of a mechanistic understanding and quantitative models of coupled Fe(III)/U(VI) reduction in FRC Area 2 sediments. This work builds on our previous studies of microbial $\mathrm{Fe}(\mathrm{III})$ and $\mathrm{U}(\mathrm{VI})$ reduction, and is directly aligned with the Scheibe et al. NABIR FRC Field Project at Area 2.

Microbial Fe(III) Reduction Studies with Shewanella putrefaciens and Geobacter sulfurreducens have confirmed that the rates of $\mathrm{Fe}(\mathrm{III})$ bioreduction depend on oxide surface area rather than oxide thermodynamic properties (Burgos et al., 2003; Roden, 2003a, b, 2005). We have conducted a theoretical analysis of the effect of Fe(II) accumulation on the long-term kinetics of oxide bioreduction (Roden, 2004), the results of which are consistent with studies where variations in mixing intensity and pre-loading of $\mathrm{Fe}(\mathrm{II})$ vs. Mn(II) showed that the rate of bioreduction by Shewanella putrefaciens decreased due to accumulation of $\mathrm{Fe}(\mathrm{II})$ at the oxide interface (Royer et al., 2004). These experiments also demonstrated the significance of mixing or flow conditions and of surface hydration for bioreduction modeling. We investigated the effects of cell density on reduction rate (Roden, 2003a; Roden and Sedo, 2003; Roden, 2005), and provided information required for simulation of oxide reduction kinetics in nonsteady-state systems in which DMRB cell density varies over time. A phospholipid fatty acid (PLFA)-based approach for quantifying changes in DMRB abundance in relatively low biomass (ca. $10^{\wedge} 5$ to $10^{\wedge} 8 \mathrm{cells} / \mathrm{mL}$ ), mineral-rich reaction systems is underway.

Iron Oxide Surface Chemistry We have studied the oxidation of sorbed Fe(II) by trace amounts of oxygen in order to evaluate issues related to subsurface reoxidation and to understand mechanisms for abiotic reduction of other electron acceptors such as uranyl at the $\mathrm{Fe}(\mathrm{III}) / \mathrm{Fe}(\mathrm{II})$ interface with water (Dempsey and Park, 2005 submitted). Our investigations revealed that sorbed Fe(II) was required for the reduction of $\mathrm{O} 2$ but that only dissolved $\mathrm{Fe}$ (II) was oxidized. We also observed conversion of hydrous ferric oxide to goethite, resulting in decreased concentration of sorbed $\mathrm{Fe}$ (II) and decreases in the rate of reduction of O2. The rate of reduction of $\mathrm{O} 2$ sharply decreased when surface density of $\mathrm{Fe}(\mathrm{II})$ exceed a limiting value. These results are consistent with previous observations, and may help to explain inhibition of bioreduction due to pre-loading of Fe(II) onto hematite.

Microbial $\mathrm{U}(\mathrm{VI})$ Reduction We have obtained kinetic parameters for reduction of soluble $\mathrm{U}(\mathrm{VI})$-carbonate complexes by G. sulfurreducens and S. putrefaciens (Burgos et al., 2005; Roden and Scheibe, 2005). We examined the potential for bioreduction of $\mathrm{U}(\mathrm{VI})$ by Geobacter sulfurreducens in the presence of synthetic $\mathrm{Fe}$ (III) oxides and natural Fe(III) oxide-containing solids (Jeon et al., 2004; Jeon et al., 2005) in which 
more than $95 \%$ of added $\mathrm{U}(\mathrm{VI})$ was sorbed to mineral surfaces. The results showed that a significant portion of solid-associated $\mathrm{U}(\mathrm{VI})$ was resistant to both enzymatic and abiotic (Fe(II)-driven) reduction, but that the rate and extent of bioreduction of $\mathrm{U}(\mathrm{VI})$ was increased due to the addition of anthraquinone-2,6disulfonate (AQDS). Other work has demonstrated that the rate of bioreduction of $\mathrm{U}(\mathrm{VI})$ can be decreased due to the presence of humic substances (Burgos et al., 2005). Overall, these findings indicate that the rate and extent of $\mathrm{U}(\mathrm{VI})$ bioreduction is strongly influenced by both aqueous and solid-phase geochemical conditions, and that the effects of certain components of natural systems and of amendments such as humic substances need to be studied in greater detail.

We have conducted long-term semicontinuous culture and column experiments on coupled Fe(III) oxide/U(VI) reduction. These experiments were conducted with natural subsurface sediment from the Oyster site in Virginia, whose Fe content and microbial reducibility are comparable to ORNL FRC sediments (Jeon et al., 2004). The results have conclusively demonstrated the potential for sustained removal of $\mathrm{U}(\mathrm{VI})$ from solution via DMRB activity in excess of the $\mathrm{U}(\mathrm{VI})$ sorption capacity of the natural mineral assemblages. Development of reaction-based numerical simulations of the experimental results are underway, and will include information on the $\mathrm{U}(\mathrm{VI})$ sorption characteristics of the Oyster sediment materials (Jeon et al., 2005). Constructed column experiments with Area 2 FRC sediments are currently underway.

$\mathrm{U}(\mathrm{VI})$ Hydrolysis and Sorption We have studied the sorption and surface precipitation of $\mathrm{U}(\mathrm{VI})$ on ferric (hydr)oxides (Jang et al., 2005b). The precipitation results as a function of pH were used to critically evaluate the significantly different published suites of hydrolysis constants for $\mathrm{U}(\mathrm{VI})$. Hydrolysis constants reported by Langmuir allowed significantly better fit of solubility results versus $\mathrm{pH}$ than could be achieved using hydrolysis constants from Grenthe. Sorption results were modelled using identical surface complexation reactions and constants, for either hematit4 or hydrous ferric oxide (Jang et al, 2005d). Experiments have been conducted using a continuous-flow membrane filtration system that allows control of the gas phase and continuous separation of permeate from retentate. These experimental equipment and protocols are currently being used to similarly evaluate the sorption of $\mathrm{U}(\mathrm{VI})$ onto aluminum (hydr)oxides and ferric (hdr)oxides (Tai et al., 2005).

Humic Chemistry We have demonstrated that humic substances inhibit the bioreduction of dissolved $\mathrm{U}(\mathrm{VI})$ and that soluble humic-U(IV) complexes can be formed (Burgos et al., 2005). We have also measured abiotic reactions between humic substances and U(VI). Kirkham (2004) measured and modeled complexation of $\mathrm{U}(\mathrm{VI})$ by humic substances as a function of $\mathrm{pH}, \mathrm{PCO} 2, \mathrm{U}(\mathrm{VI})$ concentration, and humic concentration, and demonstrated that humic substances can complex $\mathrm{U}(\mathrm{VI})$ even at neutral $\mathrm{pH}$ values and in the presence of high (ca. $30 \mathrm{mM}$ ) carbonate concentrations. These results are reported by Dempsey et al. (2005). Jang (2004) measured the abiotic reduction of U(VI) by Fe(II) sorbed to Fe(III) oxides in the presence/absence of humic substances and demonstrated that humic substances inhibited the heterogeneous reduction of $\mathrm{U}(\mathrm{VI})$. These results are reported by Jang et al. (2005a). All of these findings highlight the additional complexity that humic substances add to the system.

Reaction-Based Reactive Transport Modeling We have recently developed, validated, and documented a series of diagonalized reaction-based reactive transport computer models (HYDROGEOCHEM; Yeh et al., 2004a, b; BIOGEOCHEM; Fang et al., 2003). We have demonstrated the use of a reaction-based reactive transport model (HYDROGEOCHEM) for the simulation of biological iron reduction in natural sediment columns (Burgos et al., in preparation). Modeling investigations were conducted for both batch and column experiments. Simulations demonstrated that batch models can be upscaled to column models if the former are iteratively formulated with the later (Yu et al., 2004).

As more complex biogeochemical situations are being investigated (e.g., evolving reactivity, passivation of reactive surfaces, dissolution of sorbates), there is a growing need for biogeochemical simulators to flexibly and facilely address new reaction forms and rate laws. An approach was developed that accommodates this need to efficiently simulate general biogeochemical processes, while insulating the user from additional code modification (Fang et al., 2005). Future modeling efforts will focus on the developments and numerical simulations of reaction networks and the formulation of reaction rates that 
can better and further elucidate the mechanisms of Fe(III) oxide reduction, biosynthesis, abiotic geochemical processes, and coupled Fe(III) oxide/U(VI) reduction in sediments at the NABIR field research center.

We have also applied an analogous reaction-based model of coupled $\mathrm{Fe}(\mathrm{III})$ oxide/U(VI) reduction that has been employed in numerical simulations of $\mathrm{U}(\mathrm{VI})$ bioreduction in bench-scale (Roden and Sedo, 2003) and field-scale (Roden, 2003c) systems. This progress gives us confidence that these models can be successfully applied to field conditions that required large reaction networks and physical heterogeneity. Finally, we have developed a reaction-based model of Terminal Electron Accepting Processes and other biogeochemical reactions in a hypothetical Representative Elementary Volume of Uranium-contaminated subsurface sediment (referred to by the acronym TEAPREVU) (Roden et al., 2005). The model was developed to simulate the results of a batch slurry experiment with FRC Area 2 sediment (Mohanty et al., 2004), with the idea that the developed framework will eventually be incorporated into a field-scale reactive transport simulation of in situ biostimulation at Area 2. The model is capable of simulating time-dependent microbial population dynamics in relation to the abundance of various oxidized and reduced species and mineral phases, which in turn are a function of the input of external electron acceptors/donors and other aqueous species. Yilin Fang (fomer Ph.D. student of project co-PI Yeh) at PNNL has already implemented the model into HYDROGEOCHEM.

DELIVERABLES: Burgos, W. D., J. M. Senko, J. J. Stone, B. A. Dempsey, E. E. Roden, K. M. Kemner et al. 2005. Humic materials decrease biological uranium reduction by Shewanella putrefaciens CN32. Environ. Sci. Technol. Submitted for publication.

Burgos, W.D, J.M. Senko, J.J. Stone, B.A. Dempsey, E.E. Roden, K.M. Kemner, S.D. Kelly and B. Gu. 2005. Humic Materials Decrease Biological Uranium Reduction by Shewanella putrefaciens CN32. Environ. Sci. Technol. Submitted.

Burgos, W.D., Y.L. Fang, R.A. Royer, G.T. Yeh, J.J. Stone, B.H. Jeon and B.A. Dempsey. 2003. Reaction-Based Modeling of Quinone-Mediated Bacterial Iron(III) Reduction. Geochim. Cosmochim. Acta. 67:2735-2748.

Chen, C. W., 2005. Numerical Modeling of Dissimilatory Iron Reduction in Sediments at a Field Site. M. S. Thesis. Department of Civil and Environmental Engineering, University of Central Florida, Orlando, FL 32816. August, 2005.

Dempsey, B.A., R. Kirkham, and W.D. Burgos. 2005. Complexation of Uranyl with Humic Acid as a Function of $\mathrm{Pco} 2$ and $\mathrm{pH}$, to be submitted to Water Research.

Fang, Y., G. T. Yeh, and W. D. Burgos. 2003. A general paradigm to model reaction-based biogeochemical processes in batch systems. Water Resour. Res. 39:1083-1108.

Fang, Y., S. B. Yabusaki, and G. T. Yeh, 2005. A General Simulator for Reaction-Based Biogeochemical Processes. Computers and Geosciences (Accepted).

Fang, Y.L., S. B. Yabusaki, and G. T. Yeh, 2004. A Generic Reaction-based Biogeochemical Simulator. Proc. XV International Conference on Computational Methods in Water Resources (Miller, C. T., Farthing, M. W., Gray, W. G., and Pinder, G., eds). pp. 869-878. Chapel Hill, North Carolina, June 13-17, 2004.

Jang, J-H., B.A. Dempsey, W.D. Burgos. 2005a. Abiotic Reactions of U(VI) with Fe(II) in the Presence of Hydrous Ferric Oxide (HFO) and Hematite plus Natural Organic Matter (NOM): Sorption, Reduction, and Transformation, to be submitted to Water Research. 
Jang, J-H., B.A. Dempsey, W.D. Burgos. 2005b. Hydrolysis of Uranyl (UO22+): An Experimental Evaluation of Complexation and Solubility Constants, to be submitted to Water Research.

Jang, J-H., B.A. Dempsey, W.D. Burgos. 2005c. Similarity of Surface Reactivities of Hydrous Ferric Oxide and Hematite: Solubility, Sorption, Oxidation-Reduction Reactions, to be submitted to Environ. Sci. Technol.

Jang, J-H., B.A. Dempsey, W.D. Burgos. 2005d. Sorption and Solubility of U(VI) in the Presence of Hydrous Ferric Oxide and Hematite, to be submitted to Environ. Sci. Technol.

Jeon, B. H., M. O. Barnett, W. D. Burgos, B. A. Dempsey, and E. E. Roden. 2005. Chemical reduction of $\mathrm{U}(\mathrm{VI})$ by $\mathrm{Fe}(\mathrm{II})$ at the solid-water interface using synthetic and natural iron(III) oxides. Environ. Sci.

Technol. In press.

Jeon, B. H., S. D. Kelly, K. M. Kemner, M. O. Barnett, W. D. Burgos, B. A. Dempsey, and E. E. Roden. 2004. Microbial reduction of $\mathrm{U}(\mathrm{VI})$ at the solid-water interface. Environ. Sci. Technol. 38:5649-5655.

Mohanty, S., B. Kollah, and E. E. Roden. 2004. Biogeochemical processes and microbial community structure in ethanol-stimulated subsurface sediments. Manuscript in preparation.

Park, B., and B.A. Dempsey. 2005. Mechanisms of Heterogeneous Oxidation of Fe(II) on Ferric Oxide at Neutral pH, submitted to Environ. Sci. Technol.

Roden, E. E. 2003a. Fe(III) oxide reactivity toward biological versus chemical reduction. Environ. Sci. Technol. 37:1319-1324.

Roden, E. E. 2003b. Diversion of electron flow from methanogenesis to crystalline Fe(III) oxide reduction in acetate-limited cultures of wetland sediment microorganisms. Appl. Environ. Microbiol. 69:5702-5706.

Roden, E. E. 2004. Analysis of long-term bacterial versus chemical Fe(III) oxide reduction kinetics. Geochim. Cosmochim. Acta 68:3205-3216.

Roden, E. E. 2005. Geochemical and microbiological controls on dissimilatory iron reduction. C.R. Geosci. Submitted for publication.

Roden, E. E., and E. Sedo. 2003. Framework for numerical simulation of bacterial Fe(III) oxide reduction in circumneutral soil and sedimentary environments. EOS Trans. AGU 84(46), Fall Meet Suppl.:Abstract B32A-0375.

Roden, E. E., and T. D. Scheibe. 2005. Conceptual and numerical model of uranium(VI) reductive immobilization in fractured subsurface sediments. Chemosphere 59:617-628.

Royer R.A., B.A. Dempsey, B.H. Jeon and W.D. Burgos. 2004. Inhibition of Biological Reductive Dissolution of Hematite by Ferrous Iron. Environ. Sci. Technol. 38:187-193.

Suk, H., and G.T. Yeh. 2004. Multiphase flow modeling with general boundary conditions and phase configuration changes using fractional flow approaches. ASCE Hydrologic Engineering. Submitted.

Suk, H., and G.T. Yeh. 2004. Particle tracking algorithm for the Lagrangian finite element method under transient conditions in multi-dimensions. International J. Numerical Methods in Engineering. Submitted. 
Suk, H., and G.T. Yeh. 2004. Three-dimensional three-phase flow simulations using the LagragianEulerian approach with adaptively zooming and peak/valley capturing scheme (LEZOOMPC). ASCE Hydrologic Engineering. Submitted.

Sun, J. T. and G. T. Yeh, 2004. Modeling 3-D Coupled Variably Saturated Flow, Reactive Chemical Transport, and Heat Transfer under Complex and Mixed Reaction Systems. Proc. XV International Conference on Computational Methods in Water Resources (Miller, C. T., Farthing, M. W., Gray, W. G., and Pinder, G., eds). pp. 879-890. Chapel Hill, North Carolina, June 13-17, 2004.

Tai, Y., B.A. Dempsey, M. Russell, and W.D. Burgos. 2005. Sorption of U(VI) to Alumina, to be submitted to Environ. Sci. Technol.

Tuntoolavest, M., and W.D. Burgos. 2005. Anaerobic Phenol Oxidation by Geobacter metallireducens Using Various Electron Acceptors. Environmental Engineering Science. In press.

Yeh, G. T. and F. Zhang, 2004. An Adaptive Local Grid Refinement and Peak/Valley Capture Algorithm to Solve Nonlinear Transport Problems With Moving Sharp-Fronts. Proc. 6th International Conference on Hydroinformatics 2004 (S. Y. Liong, K. K. Phoon, and V. Babonic, eds). CD. Singapore, June 21-24, 2004.

Yu, J., A. Chen, G. T. Yeh, W. D. Burgos, and M. L. Minyard, 2004. Modeling Hematite Bioreduction under Growth Conditions. EOS, Transac. Ameri. Geophy. Union, Vol. 85(47), p. F916. December 13 17, 2004.

Zhang, F., G. T. Yeh, J. C. Parker, and S. C. Brooks, 2005. Three-Dimensional Reactive Chemical Transport Modeling In Groundwater of Watershed System. Submitted to Water Resour. Res.

COLLABORATIONS: Brian Dempsey, Penn State University Gour-Tsyh (George) Yeh, University of Central Florida Eric Roden, University of Alabama Ken Kemner, Argonne National Laboratory (ANL) Shelly Kelly, ANL John Zachara, Pacific Northwest National Laboratory (PNNL) 